\title{
Late-onset bloodstream infections of Very-Low- Birth-Weight infants: data from the Polish Neonatology Surveillance Network in 2009-2011
}

Jadwiga Wójkowska-Mach", Ewa Gulczyńska², Marek Nowiczewski², Maria Borszewska-Kornacka³, Joanna Domańska ${ }^{4}$, T Allen Merritt ${ }^{5}$, Ewa Helwich ${ }^{6}$, Agnieszka Kordek , Dorota Pawlik ${ }^{8}$, Janusz Gadzinowski ${ }^{9}$, Jerzy Szczapa ${ }^{9}$, Paweł Adamski ${ }^{10}$, Małgorzata Sulik ${ }^{3}$, Jerzy Klamka ${ }^{4}$, Monika Brzychczy-Włoch ${ }^{1}$ and Piotr B Heczko

\begin{abstract}
Background: Late-Onset Bloodstream Infections (LO-BSI) continue to be one of the most important complications associated with hospitalization of infants born with very low birth weight (VLBW). The aims of this study were to assess the epidemiology of LO-BSI together with the risk factors and the distribution of causative pathogens at six Polish neonatal intensive care units that participated in the Polish Neonatology Surveillance Network from January 1, 2009 to December 31, 2011.
\end{abstract}

Methods: The surveillance covered 1,695 infants whose birth weights were $<1501$ grams (VLBW) in whom LO-BSI was diagnosed $>72$ hours after delivery. Case LO-BSI patients were defined according to NeoKISS.

Results: Four hundred twenty seven episodes of LO-BSI were diagnosed with a frequency of $25.3 \%$ and an incidence density of 6.7/1000 patient-days (pds). Results of our multivariate analysis demonstrated that surgical procedures and lower gestational age were significantly associated with the risk of LO-BSI. Intravascular catheters were used in infants with LO-BSI significantly more frequently and/or for longer duration: Central venous cathters (CVC) (OR 1.29) and Peripheral venous catheters (PVC) (OR 2.8), as well as, the total duration of total parenteral nutrition (13 vs. 29 days; OR 1.81). Occurrence of LO-BSI was significantly associated with increased the length of mechanical ventilation (MV) (OR 2.65) or the continuous positive airway pressure (CPAP) (OR 2.51), as well as, the duration of antibiotic use (OR 2.98). The occurrence of more than one infection was observed frequently (OR 9.2) with VLBW with LO-BSI. Microorganisms isolated in infants with LO-BSI were dominated by Gram-positive cocci, and predominantly by coagulase-negative staphylococci (62.5\%).

Conclusions: Independent risk factor for LO-BSI in VLBV infants are: low gestational age and requirement for surgery. The incidence rates of LO-BSI especially CVC-BSI were higher in the Polish NICUs surveillance than those of other national networks, similar to the central- and peripheral utilization ratio.

\section{Background}

Late-Onset Bloodstream Infections (LO-BSI) continue as a critical complication associated with hospitalization of very low birth weight (VLBW) infants. LO-BSI contributes to morbidity, mortality, and other long-term adverse outcomes [1-5]. Surveillance of these infants, especially blood stream infections (BSI) was introduced in intensive care

\footnotetext{
*Correspondence: mbmach@cyf-kr.edu.pl

${ }^{1}$ Microbiology, Jagiellonian University Medical College, 18 Czysta Street, Krakow 31-121, Poland

Full list of author information is available at the end of the article
}

units in Poland [6,7] however, the epidemiology of these infections has not previously been collected systematically in Polish VLBW infants.

The epidemiology of infections among neonatal intensive care units (NICUs) in the USA has been explored through the National Healthcare Safety Network (NHSN) system of the Centers for Disease Control and Prevention (CDC); however, limited information has been available from the European countries. The biggest one, German "Krankenhaus-Infections-SurveillanceSystem”, NeoKISS (http://www.nrz-hygiene.de/en/surveillance/ 
hospital-infection-surveillance-system) began in January 2000 as a prospective surveillance system for VLBW infants $[8,9]$. The similar surveillance systems have been implemented in France: Epidemiologie des Petits Ages Gestationnels, EPIPAGE study [10] and in the United Kingdom: the Neonatal Infection Surveillance Network, neonIN [11].

The aim of this study was to assess the epidemiologic factors and microbiological spectrum of primary LOBSIs associated with or without intravascular devices together with identification of risk factors and the distribution of causative pathogens. A second aim was to implement uniform definitions, specimen acquisition, and culturing techniques for infection surveillance: continuous, systematic collection, analysis and interpretation of health-related and infections data.

\section{Methods}

Utilization of data collected in the Polish Neonatology Surveillance Network (PNSN) for the scientific purpose was approved by the Bioethics Committee of Jagiellonian University Medical College - no. KBET/221/B/2011.

Continuous prospective target surveillance of infections was conducted from 1/1/2009 through 12/31/2011 at six Polish NICUs (only teaching hospitals) which participated in PNSN. These tertiary NICUs provided care for $20 \%$ of all VLBW infants born in Poland annually. The surveillance included infants hospitalized in these NICUs whose birth weights were $<1501$ grams (VLBW) at birth until they achieved a weight of 1800 grams or died. The general fatality case rate was $16.3 \%$. The fatality case rate in subgroup of infants with a birth weight $<500$ grams was $75 \%$; thus on 1 infant reached a weight of $>1800$ grams with a LO-BSI, and 3 were transferred to other units and were not further included in the surveillance within the PNSN. All VLBW infants of suspected or documented infected were subject to registration regardless of the time of occurrence according to criteria of Gastmeier et al. (see Appendix 1) when they had clinical signs of a bloodstream infection (BSI) [8]. Pneumonia and necrotizing enterocolitis were defined also according to criteria of Gastmeier et al. [8]. LO-BSI was defined when diagnosed $>72$ hours after delivery. Clinical sepsis represented an infant where signs of infection existed but on blood culture a causative organism was not identified. Central venous catheter (CVC)associated BSI (CVC-BSI) and peripheral intravenous catheter (PVC) associated BSI (PVC-BSI) were infections associated with the use of a central or peripheral venous catheter within the preceding 48 hours prior to the onset of the infection $[8,12]$. The CVC utilization rate was 0.45 and the PVC utilization rates was 0.16 (calculated by dividing the number of days of CVC/PVC by the total number of patient days).
A surgical procedure was defined as surgery performed within an operating theater except for insertion of CVC involving a surgical incision for tissue removal or repair or to treat a surgical condition. The analysis was performed in infants prior their attaining a weight of 1800 grams in all cases. In the analysis of the relationship between LO-BSI and need for surgery, infants were included when the initial signs were observed between 3 to 30 days after operative intervention. Infants with more than one episode of infection were included; however, the addition of or change in pathogen was not necessarily indicative of a new episode of infection.

All blood specimens of at least 1 milliliter were injected into an aerobic blood culture bottle (Bactec Plus 26 Aerobic; BD Microbiology Systems) and cultured on MacConkey agar, horse blood agar (at 37 degrees C, each for $24 \mathrm{~h}$ ) and Sabourand agar (at 37 degrees $\mathrm{C}$ for 38 hours. The isolates were characterized using biochemical tests, bioMerieux identification kit API system (bioMerieux, France).

\section{Statistical methods}

These data were not subject to external validation (by researchers from other/external centers) and approximately $5 \%$ of the records were incomplete. Analysis of the impact of selected factors for the risk of LO-BSI was based on the group of infants who survived until the third day or longer. For the evaluation of the differences between the averages for the examined groups of infants, a one way analysis of variance (ANOVA) with the least significant difference test and Tukey's test were applied. For the assessment of the frequency of infections in various groups of infants the chi-square test of independence was used.

A logistic regression model was used to initially examine whether there were observations with missing data or divergent data. The elimination of outliers for each variable was quantified based on box graphs, and we calculated measures of association using a model of selecting the explanatory variables intuitively understanding that each variable can have an effect on the dependent variable. The dependent variable was the dichotomous variable: the occurrence or non-occurrence of LO-BSI. Thereafter, a formal model of logistic regression was constituted to estimate the parameters using the quasiNewton method. Analysis of the individual p-values allowed us to reject variables that were statistically insignificant. Before deciding to remove a variable, a logistic regression was performed separately for each factor (birth weight, gestational age, or requirement for surgery). The Clinical Risk Index for Babies (CRIB) score, and Apgar 1 and 5 minutes scores were also included in the logistic model. The odds ratio (OR) was used to 
determine the effect of a specific factor to increase the likelihood of LO-BSI.

A generalized linear model (GLZ) was applied to assess the significance of differences between Staphylococcus aureus, the coagulase-negative staphylocci (CNS), Enterobacteriaceae and other microorganism infection, and birth weight, gestational age, duration of hospitalization prior to the date of onset of the initial clinical sign or used of devices: CVC, PVC, mechanical ventilation (MV), and/or continuous positive airway pressure (CPAP). These models were evaluated separately for each bacterial groups. As the dependent variable was dichotomous, the binominal distribution was used. The predictors used in the model were continuous (birth weight, gestational age, duration of hospitalization), as well as, the categorical variables (use of CVC, PVC, MV and/or CPAP). Including such a set of variables in this model demands using the logit-linked function. Calculations were performed with the application of the open source library SciPy. A multivariate analysis of the influence of the risk factors on CVC-BSI identification was conducted using a classification tree learner [13,14] (Orange Biolab). A p $<0.05$ was considered statistically significant.

Our data were compared with NeoKISS surveillance system in Germany. In this analysis, data from one of six centers were not used because information about CVC and/or PVC catheterization, MV and/or CPAP was incomplete. NeoKISS data were chosen for comparison to the data from the PNSN owing to the meticulous research methods employed in this surveillance program.

\section{Results}

\section{Description of the population}

There were 1,695 newborns included in our surveillance of whom 1,243 who survived $>72$ hrs. This group was composed of 462 (27.3\%) of extremely low birth weight infants with a birth weight $<=750 \mathrm{gms}, 313(18.5 \%)$ infants with a birth weight from 751 to 999 gm, and 920 (54.3\%) infants with birth weight ranging from 1000-1500 gm. Among these 1,234 infants, 164 (9.7\%) underwent surgical procedures. The most common surgical procedure was closure of the patent ductus arteriosus (PDA) which represented $48.4 \%$ of all surgical procedures.

\section{Late-onset bloodstream infections}

There were 427 episodes of LO-BSI diagnosed representing an incidence density of 6.7/1000 patient days (pds), including 46 cases of clinical sepsis were observed (10.7\% of all LO-BSI). The onset of clinical signs of LOBSI occurred an average of 15 days after birth (SD 14.3 days; median 11 days). Mean gestational age was 28 weeks (median 27 weeks) and the mean birth weight was 1100 grams (median 880 grams). Among infants with LO-BSI birth weights were significantly lower than in the group of newborns not having LO-BSI (Table 1).

The incidence of LO-BSI among infants within various birth weight categories were significantly different. The highest incidence rate (compared to infants with higher birth weight) was confirmed in the infants with birth weights <750 grams: $44.6 \%$ vs. $27.1 \%$ (OR 2.36; $95 \%$ CI 1.60-3.47). Results of the multivariate analysis found that low gestational age $(\mathrm{p}=0.002$; OR 3.9; 95\% CI 2.99-5.12) and requirement for surgery $(\mathrm{p}<0.001$; OR $1.895 \% \mathrm{CI}$ 1.32-2.56) were significantly associated with risk of LOBSI (up to 30 days after surgery) and others (Table 2).

Those infants with LO-BSI were more frequently vulnerable to other infection such as pneumonia (OR 2.13; 95\% CI 1.52-2.97) or necrotizing enterocolitis (OR 1.55; $95 \%$ CI 1.00-2.44). The occurrence of more than one infection was observed frequently (OR 9.2; 95\% CI 6.0513.98). In the group of infants with signs of LO-BSI, we did not observe an increased mortality rate; however, early mortality associated with LO-BSI occurred usually $<7$ days after the occurrence of the initial signs of LO-BSI was $7.5 \%$.

The requirement for mechanical ventilation (OR 2.64 95\% CI 1.96-3.55) or the use of CPAP (OR 2.51; 95\% CI 1.83-3.44) were significantly more frequent among VLBW infants with LO-BSI. Analysis showed no association between the studied NICUs and the incidence rate of LO-BSI.

\section{Central and peripheral venous catheter-associated blood- stream infections}

The CVC-BSI incidence rate was 8.6/1000 CVCdays, and the PVC-BSI incidence was: 10.5/1000 PVCdays. The incidence rate of PVC-BSI and CVC-BSI in infants with birthweights of 1000-1499 grams was significantly higher than in other groups of infants (RR 1.9, $\mathrm{p}<0.001$ ). In infants with LO-BSI, compared to infants without LO-BSI, the catheters were used significantly more frequently and/or for a longer time: CVC (OR 1.2931, 95\% CI 0.93-1.79) and PVC (OR 2.8031, 95\% CI 2.06-3.81) (Table 1). Short-term use of PVC - up to 10 days - did not influence on the risk of LO-BSI.

Also, in infants with LO-BSI compared to infants without LO-BSI, total parenteral nutrition was prescribed significantly more frequently (OR $1.813,95 \%$ CI 1.25 2.64), and/or for a longer duration, average: 13 vs. 29 days (over 16 days, OR 4.3489, 95\% CI 3.17-5.96).

\section{Microbial aetiology of the LO-BSI}

Gram-positive cocci constituted $77 \%$ of the isolated pathogens from CVC-BSI. The largest group was coagulasenegative staphylococci (CNS) and Staphylococcus aureus. The dominant species among group of the CNS isolates were S. epidermidis (62.5\%), then S. haemolityicus (20\%), 
Table 1 The characteristics of infants with and without symptoms of LO-BSI, who survived to the third day and/or later

\begin{tabular}{|c|c|c|c|c|c|}
\hline \multirow{3}{*}{$\begin{array}{l}\text { Characteristics of patients } \\
\text { Gestational age [weeks] }\end{array}$} & \multirow{2}{*}{\multicolumn{2}{|c|}{$\begin{array}{l}\text { Infant's LO-BSI (-) [N=816] } \\
\text { average; } 95 \% \mathrm{Cl}\end{array}$}} & \multicolumn{2}{|c|}{ Infant's LO-BSI $(+)[\mathrm{N}=427]$} & \multirow{3}{*}{$\begin{array}{l}\begin{array}{l}\text { Statistically } \\
\text { significant } \\
\text { P-value }\end{array} \\
<0.001\end{array}$} \\
\hline & & & \multirow[b]{2}{*}{27} & \multirow[b]{2}{*}{$(27 ; 28)$} & \\
\hline & 29 & $(28 ; 29)$ & & & \\
\hline Gestational age infants who required surgery [weeks] & 26 & $(26 ; 27)$ & 25 & $(28 ; 29)$ & 0.002 \\
\hline Gestational age infants who did not required surgery [week] & 29 & $(29 ; 29)$ & 28 & $(27 ; 28)$ & $<0.001$ \\
\hline Birth weight [grams] & 1114 & $(1087 ; 1141)$ & 947 & $(920 ; 974)$ & $<0.001$ \\
\hline CVC [days] & 15 & $(14 ; 16)$ & 31 & $(27 ; 34)$ & $<0.001$ \\
\hline PVC [days] & 9 & $(8 ; 10)$ & 18 & $(16 ; 21)$ & $<0.001$ \\
\hline Mechanical ventilation [days] & 12 & $(10 ; 13)$ & 26 & $(22 ; 30)$ & $<0.001$ \\
\hline CPAP [days] & 9 & $(8 ; 9)$ & 16 & $(14 ; 17)$ & $<0.001$ \\
\hline Total parenteral nutrition [days] & 13 & $(12 ; 14)$ & 29 & $(27 ; 32)$ & $<0.001$ \\
\hline surgery in infancy*[No./\%] & 87 & 10.7 & 77 & 18.0 & $<0.001$ \\
\hline \multicolumn{6}{|l|}{ Completion of the surveillance } \\
\hline Death of the patient [No./\%] & 67 & 8.2 & 32 & 7.5 & 0.4 \\
\hline Transfer [No./\%] & 101 & 12.4 & 48 & 11.2 & 0.2 \\
\hline Body weight gain [No./\%] & 646 & 79.2 & 345 & 80.8 & 0.9 \\
\hline
\end{tabular}

* up to 30 days after surgery; $\mathrm{Cl}$ - confidence interval; LO-BSI, Late-Onset Bloodstream Infections; PROM, premature rupture of membranes; CVC, central venous catheter; PVC, peripheral intravenous catheter; CPAP, continuous nasal positive airway pressure.

S. warneri (7.5\%), S. hominis (5\%), S. xylosus $(2.5 \%)$ and S. capitis $(2.5 \%)$.

Gram-negative rods were isolated more often in PVCBSI than in CVC-BSI (Table 3), especially, Klebsiella spp which were the second most common microorganisms in PVC-BSI. Infections caused by yeast-like fungi constituted $3.8 \%$ of all the BSI cases and there were no other fungal infections.

There was no relationship between the bacterial etiology of LO-BSI, and the following: birthweight, gestational age, length of hospitalisation before the date of first signs and the use of devices analysed separately with one-factor statistical techniques.

\section{Discussion}

Our results of LO-BSI are the first to be reported by the Polish Neonatology Surveillance Network (PNSN) and from Central Europe (except Neo-KISS) based on a national program for infection surveillance and control among NICUs. Our previous report on this population within the PNSN focused on early onset infection [15].

Table 2 Crude and adjusted odds ratio (OR) and $95 \%$ confidence intervals (95\% CI) for nevborns with and without symptoms of LO-BSI (late onset bloodstream infections), who survived to the third day and/or later (2009-2011)

\begin{tabular}{|c|c|c|c|c|}
\hline \multirow[b]{2}{*}{ Characteristics of patients } & \multicolumn{2}{|c|}{ Infant's LO-BSI (-) [N= 816] } & \multicolumn{2}{|c|}{ Infant's LO-BSI $(+)[N=427]$} \\
\hline & crude OR & $95 \% \mathrm{Cl}$ & adjusted* OR & $95 \% \mathrm{Cl}$ \\
\hline Gestational age $<28$ week & 3.9 & $2.99-5.13$ & 71.808 & 71.57-72.05 \\
\hline Birth weight $<750$ grams & 2.362 & $1.60-3.48$ & 3.732 & $3.45-4.01$ \\
\hline Chorioamnionitis & 1.404 & $0.80-2.45$ & 1.185 & $0.96-1.42$ \\
\hline PROM & 1.079 & $0.78-1.48$ & 3.343 & $2.97-3.72$ \\
\hline CVC & 1.293 & $0.93-1.79$ & 2.886 & $2.49-3.27$ \\
\hline PVC & 2.803 & $2.06-3.81$ & 1.523 & $1.14-1.91$ \\
\hline Mechanical ventilation & 2.645 & $1.97-3.56$ & 12.642 & $12.31-12.98$ \\
\hline CPAP & 2.514 & $1.83-3.44$ & 2.927 & $2.62-3.24$ \\
\hline Total parenteral nutrition & 1.813 & $1.25-2.64$ & 2.912 & $2.72-3.11$ \\
\hline Surgical procedures & 1.882 & $1.28-2.77$ & 2.912 & $2.72-3.11$ \\
\hline
\end{tabular}

Adjusted for birth weight; gestational age; surgery in infancy; Clinical Risk Index for Babies, CRIB; score, Apgar 1- and 5-minute scores.

PROM, premature rupture of membranes, CVC, central venous catheter; PVC, peripheral intravenous catheter; CPAP continuous nasal positive airway pressure. 
Table 3 The occurence of the pathogens of the late-onset BSI, diagnosed >72 hours after delivery (2009-2011)

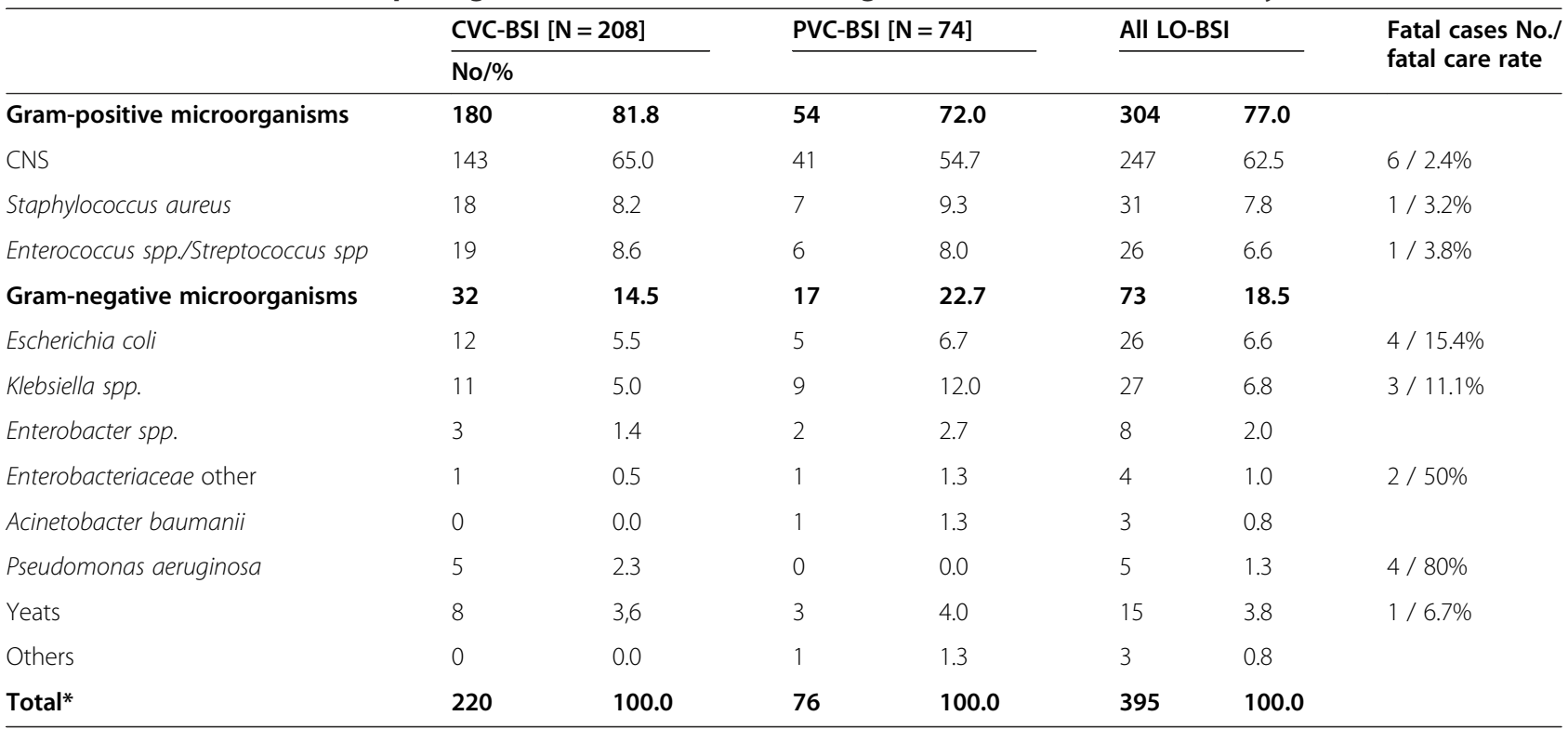

Legend:* Total microbial etiological factors is greater than the number of LO-BSI confirmed microbiologically by a mixed culture found in several infections. LO-BSI - late onset bloodstream infections, CVC-BSI - Central Venous Catheter-Associated BSI, PVC-BSI Peripheral Venous Catheter-Associated BSI; CNS - Coagulase-negative staphylococci.

LO-BSI incidence in our population are lower than those observed in other national surveillance projects. For example, in a report from the Netherlands the incidence in their groups of 742 VLBW infants was 14.9/ 1000 pds [16], and in the German NeoKISS study in their first year of reporting their incidence was 8.3/1000 pdys that included 303 VLBW infants. In the USA, the reported incidence for infants born at 28 weeks gestation or earlier was: $36 \%$ [1], while in Israel a $39 \%$ rate [17].

Our data focusing on infections associated with vascular lines do differ substantially from those published by other centers e.g. NeoKISS [18]. The CVC-BSI in our total study population was greater than $8.6 / 1000 \mathrm{CVC}$ days, while in the NeoKISS surveillance it was $13.8 / 1000$ CVC days during the initial year of reporting. However, in our population we did not identify CVC-BSI in extremely low birthweight infants (ELBW) infants <499 grams, because of their high fatality rate. However, in the NeoKISS surveillance program this group had the highest risk of CVC associated infections, as well as, PVC-BSI. Unfortunately, this severe morbidity in Polish NICUs had the highest incidence of both CVC-BSI and PVC-BSI among infants with birth weights $<1000$ gms. Our surveillance found a $60-80 \%$ increase over than reported by the NeoKISS program [9], and higher than that reported by Sengupta et al. [18].

Therefore, our results indicate the need to reduce the risk of infections associated with vascular line in Polish NICUs; Gastmeier et. al. found that after 3 years of surveillance: German NICUs reported a significant reduction in the of CVC-BSI infants from 13.8 to 10.6 cases/1000 CVC days (RR. 0.77, p=0.008) [9,19]. The German experience suggests that participation in ongoing surveillance of nosocomial infections in NICUs, requiring individual units to provide data may lead to a reduction in BSI rates when there is through participation in a national surveillance system with feedback and quality improvement [19]. Historical data from the American National Healthcare Surveillance Network [20] from 1992-2001 found that CVC- BSI was 11.3/1000 CVCdays among infants with birth weights $<750$ gm and 6.9/1000 CVCdays among infants 1001-1500 gm. However, the most current data from this surveillance network reported a 4 fold reduction in catheter associated infections in 2012 [21], and similar to rates reported from Canada [22].

The next important issue: our data also indicate a high CVC utilization rate in Polish NICUs: almost twice as likely and often (or: for a longer duration) than in the German NICUs [9].

Gram positive cocci organisms were the dominant microorganisms isolated in LO-BSI, including CNS, and especially associated with catheter associated infections. The predominance of these organisms were associated with catheter related LO-BSI in the USA [18], Japan [23], Taiwan [24] and Israel [25]. Freeman et al. first described dominance of CNS with increasing survival of ELBW infants in the 1970s [26] with longer duration of use of intravenous catheters [26]; fortunately, LO -BSI with $\mathrm{CNS}$ have not been characterized by an increased mortality [26,27]. 
Gram-negative rod infections were mostly observed among LO-BSI in patients without prolonged use of vascular lines; however, we found a lower frequency of gram-negative rod infections than have been reported in the UK [11], Taiwan [24], Germany [9], or U.S.A. [28]. In our surveillance yeast LO-BSI infections were found in $3.8 \%$ of infants $<1000 \mathrm{gm}$ and lower than that reported by Greenberg $[3,29]$, but higher than that reported by Mazoni (1.4\%) [30].

VLBW infants constitute a small group of patients undergoing surgical procedures. The literature on postsurgical in VLBW newborns has not been widely publicized. Many researchers studying the epidemiology of nosocomial infections exclude the group of VLBW infants undergoing surgery citing the diversity of this specific population that would interfere with more generalizable knowledge. In our studies the dominant problem were LO-BSI associated with infant surgery. In a publication from the U.S., risk factors for infections are late PDA closure procedures (6 or more days after diagnosis) and very low birthweight [31]. Importantly, the number of PDA closures (81 in 1243 infants who survived $>72 \mathrm{hrs}$ ) is consistent with the report by Evans, who found about $10 \%$ of infants born before 27 weeks (and 3\% of infants born at 27-29 weeks) required PDA surgical ligation [32]. Small number reports about the state of post-operative infants is insufficient $[33,34]$.

A limitation of this study is that there were not independent auditors at each site to valid submitted data. Furthermore, VLBW infants frequently have multisystem diseases resulting from immaturity such as respiratory distress syndrome and apnea or bradycardia episodes that require interventions with medical devices (MV or CPAP). For the first weeks of life limited enteral nutrition must be supplement with parenteral nutrition provided through vascular catheters that also increase their risk for infection. Infant born after maternal chorioamnionitis may receive initial antibiotic therapy that is of insufficient duration to treat neonatal sepsis, or may not have sufficient spectrum of coverage to treat organisms more prevalent in LO-BSI. As a group VLBW infants are immunologically "immature" with limited and variable transplacental antibody transfer from their mothers further increasing their risk for LO-BSI. Nonetheless by introducing common definitions, technique and quantity of blood specimen acquisition, and uniform microbiological techniques at each center in the PNSN, our surveillance provide for baseline data for quality improvement initiatives. Our focus will be to reduce the duration of CVC and PVC use to minimize the risk of LO-BSI in this population, and to meticulously care for these catheters once inserted.

\section{Conclusions}

In VLBW infants in whom use of CPAP or mechanical ventilation is nearly universal and in whom the presence of vascular catheters is nearly routine, we found that coagulase-negative staphylocci were the most common cause of LO-BSI. While rates of LO-BSI especially associated with CVC- BSI were higher in the Polish NICUs than those of other national networks, we now have evidence to inform the neonatologist into more precise selection of antimicrobial coverage when an LO-BSI is suspected. Furthermore, based on these findings it is necessary to implement a national program of infectious disease monitoring while promoting the shortest duration of CVC and PVC use as possible. There is also an ongoing need to monitor all VLBW undergoing surgery in the neonatal period for post-surgical infections to reduce the LO-BSI incidence.

\section{Appendix 1}

Definitions of infections in infants born with very low birth weight, according to [8]:

1. Bloodstream infection (BSI):

- Presence of at least two of the following: temperature $>38^{\circ} \mathrm{C}$ or $<36.5^{\circ} \mathrm{C}$ or temperature instability, tachycardia or bradycardia, apnea, prolonged capillary refill, metabolic acidosis, hypoglycemia, other signs of bloodstream infections such as lethargy;

and

- Physician already having instituted treatment for sepsis for at least five days; blood culture not done or no organism detected in blood; no apparent infection at another site (clinical sepsis)

or

- Recognized pathogen cultured from one or more blood cultures or cerebrospinal fluid and no coagulase-negative staphylococci (pathogen not related to an infection at another site) or coagulase-negative staphylococci isolated from at least one blood culture or intravascular line and one of the following: C-reactive protein $>2.0 \mathrm{mg} / \mathrm{dL}$, immature/total neutrophil ratio (I/T ratio) $>0.2$, leukocytes $<5000 / \mu \mathrm{l}$, platelets $<10000 / \mu \mathrm{l}$.

2. Pneumonia:

- one of the following criteria: chest radiography showing new or progressive infiltrates, consolidation or fluid in the lobar fissures/pleura, and

- worsening of gas exchange, and

- four or more of the following signs: worsening of gas exchange, temperature instability, new onset or increasing bradycardia $(<80 / \mathrm{min})$ or new onset or increasing tachycardia $(>200 / \mathrm{min})$, new onset or increasing tachypnea $(.60 / \mathrm{min})$ or apnea, (>20 s), new onset or increasing dyspnea 
(retractions, nasal flaring, grunting, increasing production of respiratory secretions and increasing need for suction, purulent tracheal secretions, isolation of a pathogen in respiratory secretions, Creactive protein $2.0 \mathrm{mg} / \mathrm{dl}$, immature/total ratio of neutrophil blood cells 0.2 or more)

3. Necrotising enterocolitis (NEC):

- Presence of two of the following clinical signs and symptoms without any other recognized reason at least two of the following signs: vomiting, abdominal distention, pre-feeding residuals, redness of flanks, persistent microscopic or gross blood in stools;

- and at least one of the following criteria: pneumoperitoneum, pneumatosis intestinalis, unchanging 'rigid' loops of small bowel; or histological evidence of NEC.

\section{Competing interest}

The authors declare that they have no conflict of interest

\begin{abstract}
Authors' contributions
JWM, EH and PBH designed the Polish Neonatology Surveillance Network (PNSN), JWM analyzed and interpreted the data and wrote the manuscript; TAM supported the study and wrote the manuscript; EG, MN, MBK, EH, AK and DP, EG, JG, JS, JK and MS conceived of the study, participated in its design and coordination, collected the data about VLBW neonates; JD and PA performed the statistical analysis. MBW financially supported the study. All authors read and approved the final manuscript.
\end{abstract}

\section{Acknowledgments}

This study was partially supported by a grant from the Ministry of Science and Higher Education (N N401 615340). The authors wish to thank the staff in NICUs for their help and interest in the study.

\section{Author details}

${ }^{1}$ Microbiology, Jagiellonian University Medical College, 18 Czysta Street, Krakow 31-121, Poland. ${ }^{2}$ Clinic of Neonatology, Polish Mother's Memorial Hospital-Research Institute, Lodz, Poland. ${ }^{3}$ Clinic of Neonatology and Intensive Neonatal Care, Warsaw Medical University, Warszawa, Poland. ${ }^{4}$ Institute of Theoretical and Applied Informatics of Polish Academy of Sciences, Gliwice, Poland. ${ }^{5}$ Division of Neonatology, Loma Linda University Children's Hospital, Loma Linda, California, USA. ${ }^{6}$ Clinic of Neonatology and Intensive Neonatal Care, Institute of Mother and Child, Warszawa, Poland. ${ }^{7}$ Department of Neonatal Diseases, Pomeranian Medical University, Szczecin, Poland. ${ }^{8}$ Clinic of Neonatology, Jagiellonian University Medical College, Krakow, Poland. ${ }^{9}$ Department of Neonatology, Poznan University of Medical School, Poznan, Poland. ${ }^{10}$ Institute of Nature Conservation, Polish Academy of Sciences, Krakow, Poland.

Received: 15 November 2013 Accepted: 9 June 2014

Published: 18 June 2014

\section{References}

1. Stoll BJ, Hansen NI, Bell EF, Shankaran S, Laptook AR, Walsh MC, Hale EC, Newman NS, Schibler K, Carlo WA, Kennedy KA, Poindexter BB, Finer NN, Ehrenkranz RA, Duara S, Sánchez PJ, O'Shea TM, Goldberg RN, Van Meurs KP, Faix RG, Phelps DL, Frantz ID, Watterberg KL, Saha S, Das A, Higgins RD, the Eunice Kennedy Shriver National Institute of Child Health and Human Development Neonatal Research Network: Neonatal outcomes of extremely preterm infants from the NICHD neonatal research network. Pediatrics 2010, 123:443-456.

2. Drews MB, Ludwig AC, Leititis JU, Daschner FD: Low birth weight and nosocomial infection of neonates in a neonatal intensive care unit. J Hosp Infect 1995, 30:65-72.
3. Rønnestad A, Abrahamsen TG, Medbø S, Reigstad H, Lossius K, Kaaresen PI, Engelund IE, Irgens LM, Markestad T: Sepicemia in the first week of life in a Norwegian national cohort of extremely premature infants. Pediatrics 2005, 115:e262-e268.

4. Brodie SB, Sands KE, Gray JE, Parker RA, Goldmann DA, Davis RB, Richardson DK: Occurrence of nosocomial bloodstream infections in six neonatal intensive care units. Pediatr Infect Dis J 2000, 19:56-65.

5. Friedman S, Richardson SE, Jacobs SE, O'Brien K: Systemic Candida infection in extremely low birth weight infants: short term morbidity and long term neurodevelopmental outcome. Pediatr Infect Dis J 2000, 19:499-504

6. Kübler A, Duszynska W, Rosenthal VD, Fleischer M, Kaiser T, Szewczyk E, Barteczko-Grajek B: Device-associated infection rates and extra length of stay in an intensive care unit of a university hospital in Wroclaw, Poland: international nosocomial infection control Consortium's (INICC) findings. J Crit Care 2012, 27:105:e5-e10

7. Wójkowska-Mach J, Baran M, Drwiła R, Ziętkiewicz M, Foryciarz E, Synowiec E, Romaniszyn D, Heczko PB: Factors influencing the occurrence of nosocomial blood stream infections observed in thoracic and cardiosurgical postoperative care units. Anaesthesiology Intensive Therapy 2012, 44:19-23.

8. Gastmeier P, Geffers C, Schwab F, Mitzner J, Oblader M, Ruden H: Development of a surveillance system for nosocomial infections: the component for neonatal intensive care in Germany. J Hosp Infect 2004 57:126-131.

9. Geffers C, Baerwolff, Schwab F, Gastmeier P: Incidence of healthcare-associated infections in high-risk neonates: results from the Germen surveillance system for very-low-birthweight infants. J Hosp Infect 2008, 68:214-221.

10. Vieux R, Fresson J, Hascoet JM, Blondel B, Truffert P, Roze JC, Matis J, Thiriez G, Arnaud C, Marpeau L, Kaminski M, EPIPAGE Study Group: Improving perinatal regionalization by predicting neonatal intensive care requirements of preterm infants: an EPIPAGE-based cohort study Pediatrics 2006, 118(1):84-90.

11. Vergnano S, Menson E, Kennea N, Embleton N, Russell AB, Watts T, Robinson MJ, Collinson A, Heath PT: Neonatal infections in England: the NeonIT surveillance network. Arch Dis Child Fetal Neonatal Ed 2011, 96:F9-F14.

12. European Surveillance of Healthcare-Associated Infections in Intensive Care Units. In HAl/CU Protocol v1.01 standard and light; 2010. [http://www. ecdc.europa.eu/en/aboutus/calls/Procurement\%20Related\%20Documents/ 5_ECDC_HAllCU_protocol_v1_1.pdf]

13. Dwyer $K$, Holte R: Decision tree instability and active learning lecture. Lect Notes Comput Sci 2007, 4701:128-139.

14. Esmeir S, Markovitch S, Sammut S: Anytime learning of decision trees. J Mach Learn Res 2011, 82(3):445-473.

15. Wójkowska-Mach J, Borszewska-Kornacka M, Domańska J, Gadzinowski J, Gulczyńska E, Helwich E, Kordek A, Pawlik D, Szczapa J, Klamka J, Heczko PB: Early-onset infections of very-low-birth-weight infants in polish neonatal intensive care units. Pediatr Infect Dis J 2012, 31(7):691-695.

16. Van der Zwet WC, Kaiser AM, van Elburg RM, Berkhof J, Fetter WP, Parlevliet GA, Vandenbroucke-Grauls CM: Nosocomial infections in a Dutch neonatal intensive care unit: surveillance study with definitions for infection specifically adapted for neonates. J Hosp Infect 2005, 61:300-311.

17. Makhoul IR, Sujov P, Smolkin T, Lusky A, Reichman B: Pathogen-specific early mortality in very low birth weight infants with late-onset sepsis: a national survey. Clin Infect Dis 2005, 40:218-224.

18. Sengupta A, Lehmann C, Diener-West M, Perl TM, Milstone AM: Cathete duration and risk of CVC-BSI in neonates with PICC. Pediatrics 2010, 125:648-653.

19. Schwab F, Geffers C, Barwolff S, Ruden H, Gastmeier P: Reducing neonatal nosocomial bloodstream infections through participation in a national surveillance system. J Hosp Infect 2007, 65:319-325.

20. National Nosocomial Infections Surveillance (NNIS) System Report: Data summary from January 1992-june 2001, issued august 2001. Am J Infect Control 2001, 29(6):404-421.

21. Dudeck MA, Weiner LM, Allen-Bridson K, Malpiedi PJ, Peterson KD, Pollock DA, Sievert DM, Edwards JR: National healthcare safety network (NHSN) report: data summary for 2012 device-associated module. Am J Infect Control 2013, 41(12):1148-1166.

22. Chien LYY, Macnab K, Aziz W, Andrews DD, McMillan, Lee SK: Variations in central venous catheter-related infection risks among Canadian neonatal intensive care units. Pediatr Infect Dis J 2002, 21:505-511. 
23. Babazono A, Kitajima H, Nishimaki S, Nakamura T, Shiga S, Hayakawa M, Tanaka T, Sato K, Nakayama H, Ibara S, Une H, Doi H: Risk factors for nosocomial infections in the neonatal intensive care unit by the Japanese National Infection Surveillance (JANIS). Acta Med Okayama 2008, 62:261-268.

24. Wu J-H, Chien C-Y, Tsao P-N, Chou H-S: Neonatal sepsis: a 6-year analysis in a neonatal care unit in Taiwan. Pediatr Neonatol 2009; 50(3):88-95sis in a neonatal care unit in Taiwan. Pediatr Neonatol 2009, 50(3):88-95.

25. Makhoul IR, Sujov P, Smolkin T, Lusky A, Reichmann B: Epidemiological, clinical, and microbiological characteristics of late-onset sepsis among very low birth weight infants in Israel: a national survey. Pediatrics 2002, 109:34-39.

26. Freeman J, Platt R, Sidebottom DG, Laclair JM, Epstein MF, Goldmann DA: Coagulase-negative Staphylococcal bactermia in the changing neonatal intensive care unit population. Is there an epidemic? J Am Med Assoc $1987,258: 2448-2552$.

27. Jean-Baptiste N, Benjamin DK, Cohen-Wolkowiez M, Fowler VG Jr, Laughon M, Clark RH, Smith PB: Coagulase-Negative staphylococcal infections in the neonatal intensive care unit. Infect Control Hosp Epidemiol 2011. 32:679-686.

28. Graham PL, Begg MD, Larson E, Della-Latta P, Allen A, Saiman L: Risk factors for late onset Gram-negative sepsis in low birth weight infants hospitalized in the neonatal intensive care unit. Pediatr Infect Dis J 2006, 25:113-117.

29. Greenberg RG, Benjamin DK Jr, Gantz MG, Cotten CM, Stoll BJ, Walsh MC, Sánchez PJ, Shankaran S, Das A, Higgins RD, Miller NA, Auten KJ, Walsh TJ, Laptook AR, Carlo WA, Kennedy KA, Finer NN, Duara S, Schibler K, Ehrenkranz RA, Van Meurs KP, Frantz ID, Phelps DL, Poindexter BB, Bell EF, O'Shea TM, Watterberg KL, Goldberg RN, Smith PB, Eunice Kennedy Shriver National Institute of Child Health and Human Development Neonatal Research Network: Empiric antifungal therapy and outcomes in extremely Low birth weight infants with invasive candidiasis. J Pediatr 2012, 161(2):264-269. e2.

30. Manzoni P, Stolfi I, Pugni L, Decembrino L, Magnani C, Vetrano G, Tridapalli E, Corona G, Giovannozzi C, Farina D, Arisio R, Merletti F, Maule M, Mosca F, Pedicino R, Stronati M, Mostert M, Gomirato G, Italian Task Force for the Study and Prevention of Neonatal Fungal Infections; Italian Society of Neonatology: A multicenter, randomized trial of prophylactic fluconazole in preterm neonates. New England Journal of Medcin 2007, 356:2483-2495.

31. Gonzales A, Sosenko IR, Chandar J, Hummler H, Claure N, Bancalari E: Influence of infection on patient ductusarteriosus and chronic lung disease in premature infants weighing 1000 grams or less. J Pediatr 1996, 128:470-480.

32. Evans N: Preterm patent ductus arteriosus: should we treat it?. J Paediatr Child Health 2012, 48(9):753-758. doi:10.1111/j.1440-1754.2012.02542.x.

33. Morikawa N, Kuroda T, Honna T, Kitano Y, Takayasu H, Ito Y, Nakamura T, Nakagawa S, Hayashi S, Sago H: The impact of strict infection control on survival rate of prenatally diagnosed isolated congenital diaphragmatic hernia. Pediatr Surg Int 2008, 24:1105-1109.

34. Pasquali SK, Li JS, He X, Jacobs ML, O'Brien SM, Hall M, Jaquiss RD, Welke KF, Peterson ED, Shah SS, Gaynor JW, Jacobs JP: Perioperative methylprednisolone and outcome in neonates undergoing heart surgery. Pediatrics 2012, 129:e385-e391.

doi:10.1186/1471-2334-14-339

Cite this article as: Wójkowska-Mach et al:: Late-onset bloodstream infections of Very-Low-Birth-Weight infants: data from the Polish Neonatology Surveillance Network in 2009-2011. BMC Infectious Diseases 2014 14:339.

\section{Submit your next manuscript to BioMed Central and take full advantage of:}

- Convenient online submission

- Thorough peer review

- No space constraints or color figure charges

- Immediate publication on acceptance

- Inclusion in PubMed, CAS, Scopus and Google Scholar

- Research which is freely available for redistribution 